Brit. F. vener. Dis. (1972) 48, 102

\title{
Screening out a virus-like agent from the testicular suspension of the Nichols pathogenic T. pallidum With observations on certain characteristics of the agent
}

\author{
H. GUDJONSSON*, B. NEWMAN, AND T. B. TURNER \\ From the International Treponematosis Laboratory of the Department of Microbiology, the fohns Hopkins \\ University School of Medicine, Baltimore, U.S.A., and the Department of Dermatology, Karolinska Sjukhuset, \\ Stockholm, Sweden
}

As described in previous papers (Gudjónsson and Skog, 1968: Jörgensen, 1968; Hederstedt, 1968; Gudjónsson, 1970; Gudjónsson, Newman, and Turner, 1970), rabbits inoculated with 'the Stockholm substrain' of the Nichols pathogenic Treponema pallidum in testicular emulsion prepared for the TPI test developed high fever and an increasing death rate. Pleural effusion was among the common findings post mortem.

Studies made in Baltimore in January and February, 1970, showed that the $T$. pallidum was not the sole cause of this syndrome, and strongly incriminated a contaminating viral agent (Gudjónsson and others, 1970). Since subsequent evidence also suggests that the Stockholm agent is a virus-like agent, it will be so designated in this paper.

The purpose of this paper is to describe a procedure for separating $T$. pallidum from the viruslike agent by the passage of lymph nodes after the acute disease has subsided. It is also shown that the virus-like infection can be passed serially in rabbits in the absence of $T$. pallidum. Further preliminary observations on the characteristics of the virus-like agent are also described.

\section{Material and methods \\ RABBITS}

As the experiments were carried out in both Baltimore and Stockholm, different strains of rabbits were used. New Zealand albino male rabbits were used in Baltimore and various strains of male rabbits in Stockholm (White Swedish country breed, chinchilla, French wadur, white albino Angora, black and white, and big silver). The weight when starting the experiments varied between 2.5 and $4 \mathrm{~kg}$. (average $3.2 \mathrm{~kg}$.). The animals were kept in separate cages. They were fed with antibiotic-free pellets and had free access to water. As in the earlier experiments, animals were maintained in the laboratories for about a week for observation before the experiments

These studies were supported in part by a grant from the World Health Organization, The Whitehall Foundation, and the Lennhoffs Fund of the Karolinska Institute, Stockholm.

^Present address: Department of Dermatology, Karolinska Sjukhuset, S-10401 Stockholm 60, Sweden. were started. No symptoms of disease, such as weight loss, diarrhoea, or evidence of respiratory infection, were observed during this preliminary period. Serological tests for syphilis (RPR and FTA in Baltimore and WR and TPI in Stockholm) were negative in all the rabbits used.

\section{MEASUREMENTS OF TEMPERATURE IN RABBITS}

Animals were routinely maintained in temperaturecontrolled rooms; at the Johns Hopkins Laboratory the temperature varied slightly from $15^{\circ} \mathrm{C}$. and at the Karolinska laboratory between $20^{\circ}$ and $22^{\circ} \mathrm{C}$. The rabbit temperatures were recorded in the same manner as previously described (Gudjónsson and Skog, 1968, 1970) using an ordinary rectal thermometer.

Preinoculation temperatures were not affected by the different room temperatures at the two laboratories.

Rabbit temperatures were generally taken between 9 a.m. and 9 p.m. Base-line temperatures were established for at least 3 days before inoculation. Temperatures of $39^{\circ} \mathrm{C}$. or higher were never observed before or during the day of inoculation. Temperatures of $39 \cdot 5^{\circ} \mathrm{C}$. or higher were regarded as signifying infection with the virus-like agent, and temperatures above $40 \cdot 2^{\circ} \mathrm{C}$. (Gudjónsson and Skog, 1968, 1970) reflected severe disease.

\section{SEROLOGICAL TESTS}

The TPI test was performed according to the method of Nelson and Mayer (1949) as modified by Laurell and Hederstedt (1958), and the Wassermann reaction according to the directions of Kabat and Mayer (1948) for complement fixation. Cardiolipin and a crude antigen (cholesterinized human heart extract) were used as antigens.

The rapid plasma reagin card test (RPR) and the fluorescent treponemal antibody test (FTA) were performed according to standard serological tests for syphilis (U.S. Department of Health, Education, and Welfare, 1969).

\section{Experimental results}

Passage of lymph node material 3 months after original infection

EXPERIMENT 1

Of a group of six rabbits inoculated in Baltimore on January 19, 1970, with testicular material brought 
from Stockholm and demonstrated to contain virulent $T$. pallidum, all developed high fever and only one survived. A second inoculation of this animal with the same material on February 2, 1970, evoked no fever or other sign of acute infection, indicating that it had developed an immunity to the fever-inducing agent.

By March 2 the animal had developed a typical syphiloma in the right testis in which numerous motile $T$. pallidum organisms were demonstrated by darkfield examination. A week later the animal's blood serum was positive to the RPR test in a titre of $1: 512$.

On April 22, approximately 3 months after the original inoculation, the animal was killed and its popliteal lymph nodes removed, emulsified, and centrifuged at 2,000 r.p.m. for 3 minutes to sediment cells. The supernatant was inoculated into one testis of each of three rabbits. None of these animals developed abnormal temperature rise or other symptoms of acute disease. All developed testicular syphilomas in which $T$. pallidum was demonstrated by darkfield examination, and all developed positive results to serological tests (RPR and FTA).

A second passage of testicular material from two of these animals induced no febrile reaction in four inoculated rabbits, but all developed darkfield positive syphilomas within 10 days. One of the three rabbits from the first passage was sent to Stockholm to be used for further passages. It had syphilitic lesions in the inoculated testis showing numerous $T$. pallidum 30 days after inoculation. A testicular suspension was inoculated intratesticularly into ten rabbits (second passage) in the Stockholm laboratory. No rise in temperature or deaths were observed, but all animals developed syphilitic lesions.

A third passage with testicular tissues was made 36 days later from one of the animals of the second passage group. Of ten rabbits inoculated intratesticularly, none developed a temperature rise and none died. All animals developed darkfield positive syphilitic lesions at the site of inoculation.

\section{EXPERIMENT 2}

As the lymph node material used to screen out the virus-like agent described in Experiment 1 came from only one rabbit, one of us (H.G.) performed the same experiment again in February-July, 1971, in the laboratory of the Department of Dermatology at the Karolinska Sjukhuset, Stockholm. In this experiment popliteal lymph nodes were used from three rabbits that had survived intratesticular inoculation with the testicular suspension of the original Stockholm substrain of the Nichols pathogenic $T$. pallidum containing the active agent. It should be noted that these rabbits were not reinoculated with the same suspension after 2 weeks as was done in Experiment 1. This did not influence the results of the experiment. The time scheme described in Experiment 1 was followed and the material from the three originally inoculated rabbits was kept in different lines during the subsequent serial passages. Already, in the second testicular passage, a good yield of motile treponemes was obtained after 10 days. No rises in temperature and no deaths were observed. The second passage consisted of nine rabbits, three from each of the originally inoculated rabbits.

At the time of writing a serial passage has been made every 7 to 10 days from two of the rabbits from the second passage. Ten passages are recorded, using a total of 50 rabbits and no sickness or deaths were observed.

Challenge of rabbits with virus-like agent containing material from Experiment 1

As described in earlier papers (Gudjónsson and Skog, 1968, 1970; Gudjónsson and others, 1970), with possibly rare exceptions, rabbits which survive do not react with fever or death on further challenge with the virus-like agent. In order to establish that the fever-producing virus-like agent had been screened out by the lymph node passage, described above, four rabbits from the third testicular passage were challenged 24 days later with the original testicular suspension containing the virus-like agent. All four rabbits became sick with high fever on the 3rd-4th post-inoculation day, and two died on the 6th and 9th day respectively. These reactions indicate a lack of immunity, which strongly suggests that they had not been previously infected with the virus-like agent.

Subsequent experience with the Stockholm substrain of Nichols T. pallidum from Experiment 1

Rabbits from the first and second passages from the laboratory in the Department of Dermatology at the Karolinska hospital were sent to the National Bacteriological Laboratory in Stockholm. This material, which no longer caused fever symptoms or death, was used as a source material for the TPI test and routinely passed at weekly intervals. During the next 4 months twenty consecutive intratesticular passages were made using 200 rabbits without any deaths (Hederstedt, 1971).

In the middle of December, 1970, however, there was a recurrence of sporadic deaths among the inoculated rabbits showing the same symptoms as described earlier, indicating that the virus-like agent was again present.

Going back to the original pool made from a 
rabbit brought from Baltimore and maintained in liquid nitrogen, post-inoculation deaths began to occur after three more passages. On testing the 4th and 10th passage material which had been maintained in liquid nitrogen, deaths again appeared in the second passage of this material. It should be noted that all these sporadic deaths occurred during the same period, the second half of December, 1970 (Hederstedt, 1971).

\section{Infectivity of lymph nodes during acute disease}

Popliteal lymph nodes from a rabbit inoculated intratesticularly with the Stockholm substrain of $T$. pallidum containing the virus-like agent developed the symptoms described above and died on the 4th day after the inoculation. The popliteal lymph nodes were removed at necropsy and kept in liquid nitrogen from January 23, 1970, until May 3, 1971. Emulsion of these lymph nodes was made in sterile saline $1: 3$ and inoculated intratesticularly in three rabbits. All developed high fever on the 3rd day after inoculation, two died on the 5th and 6th day respectively, and the third died on the 11th day. Autopsy showed the same gross evidence as described previously (Gudjónsson and Skog, 1968, 1970; Jörgensen, 1968; Gudjónsson and others, 1970).

This experiment shows, as was expected, that rabbits dying in the acute stage of the disease harbour the virus-like agent in the lymph nodes as well as in other tissues (testis, pleural fluid, etc.). The experiment was repeated, using three other rabbits as the source of lymph node material, with the same results.

\section{Inoculation with lymph nodes from immune rabbits}

Two rabbits that had recovered after inoculation with the active agent were killed and the popliteal nodes were removed on the 28th day after the original inoculation. Emulsions of these lymph nodes were made in the same manner as described above and inoculated intratesticularly into four rabbits. There was no rise in temperature and no deaths were observed.

\section{Passage of the virus-like agent in the absence of \\ T. pallidum}

In a previous paper (Gudjónsson and others, 1970) the serial intratesticular passage was described of pleural fluid or other tissue from rabbits that died of the acute virus-like infection. In none of this material were treponemes detected by darkfield examination, although the material obviously contained the virus-like agent in that most rabbits receiving it became sick and died. Six rabbits receiving this material survived and were observed for 6 weeks, 10 weeks, 3 months (2), 7 months, and 10 months, respectively, without showing signs of syphilitic infection and none became seroreactive to the RPR and FTA tests. Although lymph node passage was not made from these animals, we believe that the evidence is reasonably conclusive that the tissue containing the virus-like agent from the source animals was free from $T$. pallidum.

\section{Observations on the filterability and temperature resistance of the virus-like agent FILTRATION EXPERIMENTS}

These were made with both pleural fluid and testicular emulsions known to contain the virus-like agent. MF-Millipore Filters*-were used serially in diminishing pore sizes, from $1.5 \mu \mathrm{m}$. to $0.45 \mu \mathrm{m}$. as a preinfectivity test procedure. The material was then serially passed through smaller filters, and $0.5 \mathrm{ml}$. of each of these filtrates was inoculated intratesticularly into two or four rabbits. The same quantity of unfiltered material was similarly inoculated into two to four rabbits as controls.

After passing the pleural fluid serially through 1.5 and $0.45 \mu \mathrm{m}$. filters, it was put serially through filters with the following pore sizes: $0 \cdot 1,0.025$, and $0.01 \mu \mathrm{m}$. The results are shown in Table I. It will be noted that all rabbits inoculated with these filtrates developed an abnormal rise in temperature, most of them to $40 \cdot 2^{\circ} \mathrm{C}$. or higher, and that half the animals died. These results indicate that the virus-like agent is of very small size.

\section{TESTICULAR MATERIAL}

After centrifugation of the testicular emulsion at 2,000 r.p.m. for 3 minutes, the supernatant fluid was passed serially through $1.5 \mu \mathrm{m}$. and $0.45 \mu \mathrm{m}$. MF-Millipore filters, and then serially through filters of pore size $0 \cdot 22,0 \cdot 1$, and $0.01 \mu \mathrm{m}$. Two rabbits were inoculated intratesticularly with $0.5 \mathrm{ml}$. of these filtrates. The results are shown in Table I.

Rabbits inoculated with material which had passed through 0.22 and $0.1 \mu \mathrm{m}$. filters developed a febrile disease, with one of the pair dying in each group. However, of the two rabbits inoculated with the filtrate of the $0.01 \mu \mathrm{m}$.-size filter, neither developed evidence of a febrile disease.

\section{RESISTANCE OF THE AGENT TO HEAT}

It has previously been reported that heating testicular suspension containing the Stockholm substrain of the Nichols pathogenic $T$. pallidum known to contain the virus-like agent to $56^{\circ} \mathrm{C}$. for 40 minutes and

^Millipore Corporation, Bedford, Massachusetts. 
TABLE I Filtration of infective material

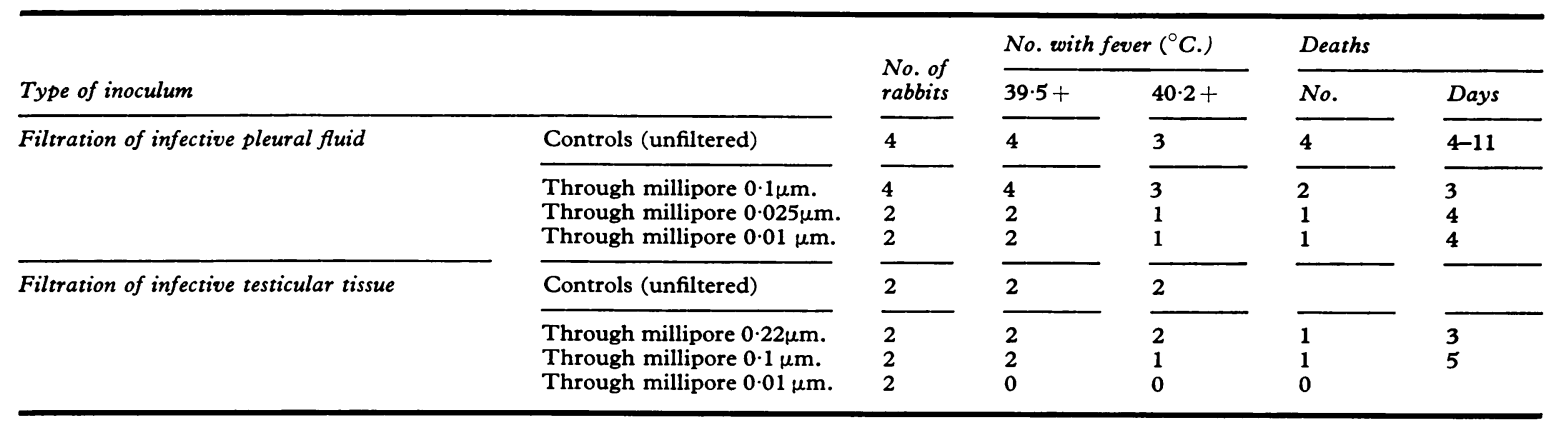

then after an 8-hour interval for 30 minutes in the water bath did not inactivate the agent, because disease was induced in inoculated rabbits (Gudjónsson and Skog, 1968). Subsequently one of us (B.N.) heated pleural fluid for one hour at $56^{\circ} \mathrm{C}$. with the same results; inoculation of the heated material gave rise to a febrile disease in seven rabbits, with three deaths.

Later, both undiluted pleural fluid and the supernatant of a 10 per cent. testicular emulsion in saline were heated for one hour at $65^{\circ}$ and $85^{\circ} \mathrm{C}$ respectively. The pleural fluid clotted during the heating, particularly at $85^{\circ} \mathrm{C}$. After being removed from the water bath, the clots were minced and allowed to cool for 1 hour at room temperature. No clotting was observed in the testicular suspension during the heating process. Both the supernatant of the minced pleural fluid and the testicular suspension were diluted with saline $1: 3$, and $0.5 \mathrm{ml}$. of each suspension was inoculated intratesticularly into three rabbits each to test for infectivity. Four rabbits were inoculated with the untreated material: two with pleural fluid and two with testicular emulsion.

All the controls developed typical fever reaction and three out of four died within 7 days. None of the rabbits that received the heated material developed fever or showed other signs of disease. The critical temperature therefore seems to be between $56^{\circ}$ and $65^{\circ} \mathrm{C}$ (Table II).

\section{Discussion}

Contamination of the Nichols strain of $T$. pallidum by a virus-like agent lethal to rabbits has caused great inconvenience in laboratories performing the TPI test, especially in the Scandinavian countries. The authors (Gudjónsson and others, 1970) suggested two methods by which the Nichols strain might be freed from this contaminating virus-like agent:

(1) Passage through other laboratory animals, such as hamsters and mice, which are not susceptible to the virus-like agent, but do permit the multiplication of $T$. pallidum;

(2) Transfer of rabbit lymph nodes long after the original inoculation, at a time when $T$. pallidum is known to be commonly present, while the viruslike agent may have disappeared.

It is this second method to which the experiments reported above have been directed. It should be noted that Skovgaard Jensen (1971) has reported that the passage of material containing both the Nichols strain of $T$. pallidum and the virus-like agent through hamsters has also resulted in what appears to be a separation of the two.

The experiments reported here show that the pop-

\section{TABLE II Inactivation of infective material by heating}

\begin{tabular}{|c|c|c|c|c|c|c|}
\hline Type of inoculum & & $\begin{array}{l}\text { No. of } \\
\text { rabbits }\end{array}$ & \multicolumn{2}{|c|}{ No. with fever $\left({ }^{\circ} \mathrm{C}.\right)$} & \multicolumn{2}{|c|}{ Deaths } \\
\hline \multirow[t]{2}{*}{ Inactivation by heating infective pleural fuid } & Controls (unheated) & 2 & 2 & 2 & 2 & $6-8$ \\
\hline & $\begin{array}{l}\text { To } 65^{\circ} \mathrm{C} \text {. for } 60 \mathrm{~min} \text {. } \\
\text { To } 85^{\circ} \mathrm{C} \text {. for } 60 \mathrm{~min} \text {. }\end{array}$ & $\begin{array}{l}3 \\
3\end{array}$ & $\begin{array}{l}\mathbf{0} \\
\mathbf{0}\end{array}$ & $\begin{array}{l}\mathbf{0} \\
\mathbf{0}\end{array}$ & $\begin{array}{l}0 \\
0\end{array}$ & \\
\hline \multirow[t]{2}{*}{$\begin{array}{l}\text { Inactivation by heating infective testicular } \\
\text { suspension }\end{array}$} & Controls (unheated) & 2 & 2 & 2 & 1 & 7 \\
\hline & $\begin{array}{l}\text { To } 65^{\circ} \mathrm{C} \text {. for } 60 \mathrm{~min} . \\
\text { To } 85^{\circ} \mathrm{C} \text {. for } 60 \mathrm{~min} \text {. }\end{array}$ & $\begin{array}{l}3 \\
3\end{array}$ & $\begin{array}{l}\mathbf{0} \\
\mathbf{0}\end{array}$ & $\begin{array}{l}\mathbf{0} \\
\mathbf{0}\end{array}$ & $\begin{array}{l}0 \\
0\end{array}$ & \\
\hline
\end{tabular}


liteal lymph nodes of rabbits infected with the contaminated Nichols strain of T. pallidum contain the virus-like agent early in the course of the disease, but later, at a time when the rabbit is immune to re-inoculation of the virus-like agent, the lymph nodes appear to be free of this agent. This is true in practice, since inoculation of these nodes into normal rabbits does not induce a febrile illness, and subsequent passage of this material for the TPI test as previously mentioned (Hederstedt, 1971), indicated that it remained free of the virus-like agent for many passages. Experiment 2 further shows that our theory of screening out the virus-like agent by lymph node passage is effective.

In a biological sense, it is difficult to be certain that the virus-like agent was completely eliminated, since after a number of passages deaths again occurred. It is not known whether the virus-like agent had been re-introduced from one of the passage rabbits, or whether reactivation of the original virus-like agent had occurred.

As noted in a previous paper (Gudjónsson and others, 1970), the Baltimore substrain of the Nichols strain of $T$. pallidum seems also to carry this viruslike agent. Under conditions of more leisurely passage no acute infection is induced in rabbits, yet most of such rabbits proved to be immune on subsequent challenge with the Stockholm virus-like agent.

The epidemiological observations made by Hederstedt (personal communication, 1964) in the National Bacteriological Laboratory in Stockholm indicate that rabbit deaths after inoculation of the Nichols strain began to rise rather rapidly in 1961 after 8 years in which rabbit deaths after inoculation of Nichols T. pallidum were few. The first year (1961) only X-ray treated rabbits showed this rise in mortality but by the next year no difference in the increase in deaths of X-ray treated and untreated animals was observed. A similar rise occurred about the same time in laboratories in Copenhagen and Oslo which were using the same strain of $T$. pallidum. No ready explanation of this phenomenon can be offered at this time.

The practical conclusion to be drawn from these observations is that rapid passage of the Nichols strain of $T$. pallidum, once it seems to be freed of the viruslike agent, is to be avoided. In laboratories performing the TPI test frequently, this can be accomplished by preparing a large pool of $T$. pallidum-containing material which does not induce a febrile disease in rabbits, and preserving the pool in liquid nitrogen for repeated induction of syphilitic lesions in rabbits as a source of $T$. pallidum. This general method of procedure has long been used in many laboratories that prepare virus vaccines.
With regard to the limited observations on certain other characteristics of the 'Stockholm viruslike agent', the evidence suggests that it is among the smallest of viruses as determined by filtration experiments, although it is recognized that filtration methods are not altogether reliable in determining size.

The nature of the material being filtered may have been responsible for the apparently divergent results between the pleural fluid and testicular material. It seems more likely, however, that the critical pore size through which this virus-like agent will pass was being reached: obviously more experiments are required to obtain definitive data.

Direct visualization and perhaps centrifugation through gradient media are desirable if the agent can be grown in vitro. The experiments on inactivation by heat are merely preliminary in nature and yield only qualitative data; more definitive tests could be made where an in vitro system is available. Previous experiments (Gudjónsson and others, 1970) have shown that the virus-like agent is not readily neutralized by serum of rabbits known to have acquired immunity.

\section{Summary and conclusions}

(1) Separation of the Nichols strain of T. pallidum, which for many years has been contaminated with a virus-like agent causing fever and death in rabbits, was effected by the transfer of popliteal lymph nodes from surviving infected rabbits, 3 months after initial inoculation.

(2) The virus-like agent passed through an M.F.Millipore filter of pore size $0.01 \mu \mathrm{m}$, indicating that it is among the smaller known viruses.

(3) A temperature of $65^{\circ} \mathrm{C}$. for 1 hour inactivated the virus-like agent, whereas a temperature of $56^{\circ} \mathrm{C}$. for 1 hour did not do so.

(4) Rapid passage of the Nichols strain of T. pallidum appears to be conducive to activation of the contaminating 'Stockholm virus-like agent' and is to be avoided when possible. It is suggested that a pool of virus-like agent-free material containing the Nichols strain of $T$. pallidum maintained in liquid nitrogen is a more satisfactory source of inoculum for the induction of syphilomas for use in the TPI test.

\section{References}

Gudjónsson, H. (1970) Brit. F. vener. Dis., 46, 318

-, NeWMAN, B., TURNER, T. B. (1970) Ibid., 46, 435

- and Skog, E. (1968) Proceedings 18th Meeting of

Scandinavian Association of Dermatology, Turku,

Finland.

HederstedT, B. (1964) Personal communication 
Hederstedt, B. (1968) Personal communication (1971) Personal communication

JÖRGENSEN, B. B. (1968) Z. Versuchstierk., 10, 46

KABAT, E. A., and MAYER, M. M. (1948) 'Experimental Immuno-chemistry'. Thomas, Springfield, Ill.

LAURell, A.-B., and Hederstedt, B. (1958) Acta path. microbiol. scand., 44, 88

NeLson, R. A., and MAYER, M. M. (1949) F. exp. Med., 89, 369

Skovgaard Jensen, H. J. (1971) Acta path. microbiol. scand., Section B., 79, 124

U.S. Department of Health, Education and Welfare (1969) 'Manual of Tests for Syphilis'. PHS Publication No. 411. Government Printing Office, Washington, D.C.

Étude d'un agent ressemblant à un virus présent dans les suspensions de Treponema pallidum pathogène Nichols, d'origine testiculaire. Remarques sur certaines caractéristiques de cet agent

\section{SOMMAIRE}

(1) L'isolement d'une souche Nichols de $T$. pallidum, qui pendant de nombreuses années a été contaminée par un agent ressemblant à un virus entraînant fièvre et mort chez les lapins, fut effectué par transfert des ganglions lymphatiques poplités à partir de lapins survivants, 3 mois après l'inoculation initiale.

(2) L'agent passe à travers un filtre Millipore-MF à trous de $0,01 \mu \mathrm{m}$, ce qui indique qu'il est parmi les plus petits virus connus.

(3) Cet agent ressemblant à un virus est inactivé par un chauffage à $65^{\circ} \mathrm{C}$. pendant une heure alors qu'il ne l'est pas par une heure à $56^{\circ} \mathrm{C}$.

(4) Le fréquent passage de la souche Nichols de $T$. pallidum semble entraîner l'activation du 'Stockholm virus-like agent' et doit être autant que possible évité. On pense que la conservation, en azote liquide, d'un 'pool' de matériel exempt de cet agent et contenant la souche Nichols de $T$. pallidum est une source d'inoculums plus satisfaisante pour la création des orchites utilisées dans le test d'immobilisation. 